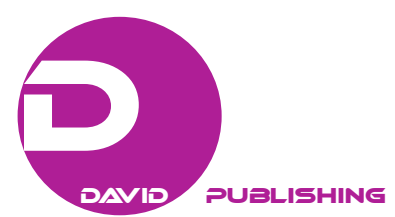

\title{
Chinese Real Estate Indices Prior to the REIT Legislation
}

\author{
Kyriaki Begiazi \\ Hellenic Balcanian Holdings, Athens, Greece
}

\begin{abstract}
Real Estate Investment Trusts (REITs) play an important role in the modern financial system as they provide investors with a liquid stake in real estate. This study investigates the real estate stock market in China during the period of July 2001-December 2015, prior to the Chinese REIT legislation. The descriptive statistics of the Shanghai and Shenzhen real estate indices are estimated along with the general index of each stock exchange. The results suggest that the general index of each stock market has a significant impact on real estate stock returns. Therefore, the real estate stock market may not be able to completely isolate its performance from the general stock market trend. Finally, various GARCH and asymmetric EGARCH models are applied to the time series daily return under a quantitative approach. Shanghai real estate index reports asymmetric transition dynamics for positive and negative shocks and the asymmetry of the volatility response to news seems to be present.
\end{abstract}

Keywords: GARCH, EGARCH, asymmetries, volatility, time series, returns

\section{REITs Background}

Real estate investment trusts (REITs) were first introduced in the United States in 1960. Since then they experienced strong growth in the rest of the world. REITs are a great tool for investors to incorporate in their portfolio real estate assets with the benefits of liquidity and the advantage of diversification potential.

Besides the United States, the largest and most liquid REIT stocks are in Japan, Hong Kong, Singapore, and Australia. In these countries, there is a god deal of tax benefits that reinforce the real estate companies. However, investors are out of China, one of the most significant Asian economies. This could change in the coming years, as China has taken steps to open up its real estate market to outside capital.

The two main stock exchanges in mainland China refer to Shanghai and Shenzhen Stock Exchange. The first approved REIT to be introduced in Shenzhen (Shanghai) is made up of commercial properties from China Vance Co. and receives cash flows from rental incomes. This is the Penghua-Qianhai-Vanke REIT that has gone public in late June 2015. But the key missing element from China's new regime is the tax benefits.

Ooi, Newell, and Sing (2006) studied the Asian REIT market and concluded that governments have an important role in the success of the REIT markets. Another plus is the improvement of the operation and efficiency of the Asian real estate organizations that have adopted the REIT regime. REITs in Japan and Singapore have performed very well. Wang, Sun, and Chen (2009) presented a qualitative analysis of the Chinese market and suggestions for a future REITs industry. Their study verifies the main problem of the unfavorable legislation and taxes environment. Quek and Ong (2008) showed that there is a strong demand for Chinese REITs, by exploring two Hong Kong REITs and one from Singapore that have securitized Chinese

Kyriaki Begiazi, Ph.D., Financial Department, Hellenic Balcanian Holdings, Athens, Greece.

Correspondence concerning this article should be addressed to Kyriaki Begiazi, No. 1 Ita str., Athens 16777, Greece. 
property assets. They believed that the Chinese REIT legislation could lead to a better regulated real estate market. Zhang and Fung (2006) found that the stock composite index is significant in the explanation of Chinese housing-price movements. They have also found that China's real estate market and the stock market are systematically negatively related due to the fund flows and proposed redirection of funds from the housing market to the stock markets.

\section{Research Questions}

Due to the potential development of the REIT market in China, this study explores the real estate indices of the two Chinese stock exchanges. This gives an insight on the already-listed real estate companies in China. Furthermore, the research takes into account the impact of the general stock market on the real estate related companies stock returns. As Gyourko and Keim (1992) concluded by analyzing the returns of different real estate-related firms in United States, the stock market reflects information about real estate markets.

The central question addressed in the present study was the degree of dependence between the real estate index and the general index of each Chinese stock market. To explore this question, we tested various GARCH models in order to find the one that can best describe the real estate index movements in accordance with the general index. The next question regards the impact of news on volatility. In other words, good and bad news do not have the same effect on the volatility.

This quantitative approach aims to explore the real estate indices of the two main stock exchanges in mainland China: Shanghai and Shenzhen stock exchange. This can help all the parties that are interested in the recent Chinese REIT development to have an insight into the real estate indices of the stock market. The introduction of the general stock market returns as an explanatory variable in their mean and variance equation benefit investors to explore any portfolio diversification potential in the real estate stock market.

Chinese REITs are a well anticipated investment instrument. The uniqueness of our analysis that adds value to the existing literature is based on the fact that the present study is a useful insight in the real estate stock market before the entrance of the real estate investment trusts. It highlights the current market condition and helps investors to understand the movements and characteristics of the real estate index in comparison with the general stock market index. Additionally, it takes into account two of the main Chinese stock markets: Shanghai and Shenzhen stock exchange as a comparative figure. China still needs to work out a lot regarding the REIT tax structure, but the general moves point to progress. Investors will have more opportunities for portfolio diversification as more REITs get listed in the stock exchanges across Asia.

The rest of this paper is organized as follows: Section 3 briefly details the research methodology. Subsequently, section 4 provides the research analysis and it is divided into two parts, the first presents the dataset and the second demonstrates the empirical results. The final section summarizes the results and discusses the main outcomes.

\section{Research Method}

\section{Research Framework}

The Chinese real estate indices are explored under various GARCH models that allow the introduction of the best-fitted model. EGARCH models allow market volatility to respond asymmetrically to positive and negative shocks. GARCH models are often much more parsimonious than ARCH models. GARCH models are better to capture the nature of volatility and incorporate much of the information than a much larger ARCH 
model with large numbers of lags. Especially in asymmetric GARCH models due to the leverage effect with asset prices, a positive shock could have less effect on the conditional variance compared to a negative shock. Glosten, Jagannathan, and Runkle (1993) showed that asymmetric adjustment was an important consideration with asset prices. The model applied in this study exponential autoregressive conditional heteroskedastic (EGARCH) has additional leverage terms in order to capture asymmetries in volatility.

\section{Time Series Modeling}

The modeling approach adopted here is based on that used by Bollerslev (1986). The GARCH model can be specified as follows:

$$
\begin{gathered}
\text { Mean equation: } R E_{t}=\beta_{0}+\beta_{1} R E_{t-1}+\beta_{2} G I_{t}+u_{t} \\
\text { GARCH }(1,1): h_{t}=a_{0}+a_{1} h_{t-1}+a_{2} u_{t-1}^{2}+a_{3} G I_{t}
\end{gathered}
$$

$R E$ variable represents the real estate index of each Chinese stock market and it is the dependent variable in the conditional mean equation. The independent variables are the lagged 1-day $R E$ return and the GI (the general index of each stock market). Equation $h_{t}$ refers to the conditional variance equation of each asset and $u_{t}$ defines the error term. The analysis consists of all the possible GARCH $(p, q)$ models with $p=1,2$ and $q=$ 1 , 2. Where $p$ is the order of the GARCH term $(h)$ and $q$ is the order of the ARCH term $\left(u^{2}\right)$.

$$
\begin{aligned}
& \text { GARCH }(1,2): h_{t}=a_{0}+a_{1} u_{t-1}^{2}+a_{2} h_{t-1}+a_{3} h_{t-2}+a_{4} G I_{t} \\
& \text { GARCH (2, 1): } h_{t}=a_{0}+a_{1} u_{t-1}^{2}+a_{2} u_{t-2}^{2}+a_{3} h_{t-1}+a_{4} G I_{t} \\
& \text { GARCH (2, 2): } h_{t}=a_{0}+a_{1} u_{t-1}^{2}+a_{2} u_{t-2}^{2}+a_{3} h_{t-1}+a_{4} h_{t-2}+a_{5} G I_{t}
\end{aligned}
$$

A major restriction of the proposed GARCH specifications is the fact that they are symmetric. The only factor under consideration is the absolute value of the innovation and not its sign due to the restriction that the residual term is squared. Therefore, in these models, a big positive shock will have exactly the same effect in the volatility of the series as a big negative shock of the same magnitude. However, it has been observed that negative shocks (or "bad news") in the stock market have a larger impact on volatility than positive shocks (or "good news").

The exponential GARCH or EGARCH model was first developed by Nelson (1991), and the variance equation for this model is given by:

$$
\log \left(h_{t}\right)=a_{0}+a_{1}\left|\frac{u_{t-1}}{\sqrt{h_{t-1}}}\right|+a_{2} \frac{u_{t-1}}{\sqrt{h_{t-1}}}+a_{3} \log \left(h_{t-1}\right)+a_{4} S P_{t}
$$

In the EGARCH equation the left side is the log of the variance series. Therefore the estimates of the conditional variance are guaranteed to be non-negative. This property makes the leverage effect exponential instead of quadratic and allows the EGARCH model to test the existence of any asymmetries. Parameter $a_{2}$ indicates these asymmetries. If $a_{2}$ equals to zero, then the model is symmetric but if $a_{2}<0$, then positive shocks (good news) generate less volatility than negative shocks (bad news). Additional EGARCH tested models’ variance representations are presented below:

$\operatorname{EGARCH}(1,2): \log \left(h_{t}\right)=a_{0}+a_{1}\left|\frac{u_{t-1}^{2}}{\sqrt{h_{t-1}}}\right|+a_{2}\left(\frac{u_{t-1}}{\sqrt{h_{t-1}}}\right)+a_{3} \log h_{t-1}+a_{4} \log h_{t-2}+a_{5} G I_{t}$

$\operatorname{EGARCH}(2,1): \log \left(h_{t}\right)=a_{0}+a_{1}\left|u_{t-1}^{2} / \sqrt{h_{t-1}}\right|+a_{2}\left|u_{t-2}^{2} / \sqrt{h_{t-2}}\right|+a_{3}\left(\frac{u_{t-1}}{\sqrt{h_{t-1}}}\right)+a_{4} \log h_{t-1}+a_{5} G I_{t}$ 
$\operatorname{EGARCH}(2,2): \log \left(h_{t}\right)=a_{0}+a_{1}\left|u_{t-1}^{2} / \sqrt{h_{t-2}}\right|$
$+a_{2}\left|u_{t-2}^{2} / \sqrt{h_{t-2}}\right|+\left(\frac{u_{t-1}}{\sqrt{h_{t-1}}}\right)+a_{4} \log h_{t-1}+a_{5} \log h_{t-2}+$
$a_{6} G I_{t}$

\section{Research Analysis}

\section{Research Subject}

The empirical tests conducted in this paper utilize the real estate indices of two Chinese stock exchanges: Shanghai (SSE) and Shenzhen (SZSE). The Shanghai real estate index is represented in the empirical results as SSE_RE and the Shenzhen real estate index as SZSE_RE. The dataset comprises of daily data from July 2001 to December 2015. The sample consists of 3,772 observations for each examined index. The general index of each stock market is used as the proxy for the market portfolio. The SSE composite (SSE_GI) and the SZSE component index (SZSE_GI) are benchmarks for Shanghai and Shenzhen stock market respectively. Consequently, the equations in the prior time series modeling section use the $R E$ and $R I$ variable as the representation of the real estate and general index respectively.

\section{Empirical Results}

Figure 1 shows the price movement of the four Chinese indices under examination. From 2006 to 2007 there is an upward trend that has been followed by a downward movement reaching its lowest point around December 2008. In 2015, a second upward movement was observed, which hit the roof in the middle of the year. The real estate indices seem to follow their stock market's general index movements.

Some descriptive statistics of the respective return series are outlined in Table 1, detailing the first four moments of each series. The values of the coefficients of skewness, kurtosis together with the large Jarque-Bera statistics lead to the rejection of the null hypothesis of a normal distribution. Heteroskedasticity is also present as indicated by the high value of the LM-statistic. It is clear that all series exhibit cases of volatility clustering requiring that the estimation should include ARCH-type processes. All the time series have negative skewness and kurtosis greater than 3, which indicates leptokurtic distributions. The real estate indices have higher mean return than their general indices. This higher mean returns designate that the real estate indices are slightly riskier than the general market. This is also verified by the higher standard deviation which indicates that the returns are spread out over a wider range of values.

Any possible asymmetries in the news are examined using the exponential GARCH approach. The general index of each stock market is used as a benchmark that give as an indication of the general stock market effect on the real estate related stock returns. The estimated GARCH models are the GARCH $(1,1)$, GARCH $(1,2)$, GARCH $(2,1)$, and GARCH $(2,2)$. Table 2 contains the Bayesian information criterion (BIC) or Schwartz criterion of the tested models. This information criteria is developed by Schwarz (1978) and is calculated by the equation: BIC $=-2 * \ln ($ likelihood $)+\ln (\mathrm{N}) * \mathrm{k}$. When fitting models, this information criteria is used in order to select the most suitable conditional variance model.

Table 3 summarizes the best model selection based on the Schwarz (1978) information criteria including the analytical presentation of each model's regression coefficients. Shanghai real estate index has a negative $a_{2}$ coefficient, which indicates that positive shocks generate less volatility than negative shocks. This means that the volatility of its real estate index returns increases more after bad news than after good news. Volatility seems to react asymmetrically to the sign of the shocks. The positive relationship between the real estate index 
returns and its own lagged values is also verified by the statistically positive coefficient $\beta_{1}$. Moreover, the general index returns have a positive effect on the real estate index mean and variance equation. The statistically positive coefficients $\beta_{2}$ and $\alpha_{6}$, clearly indicate an interaction between the two indices.
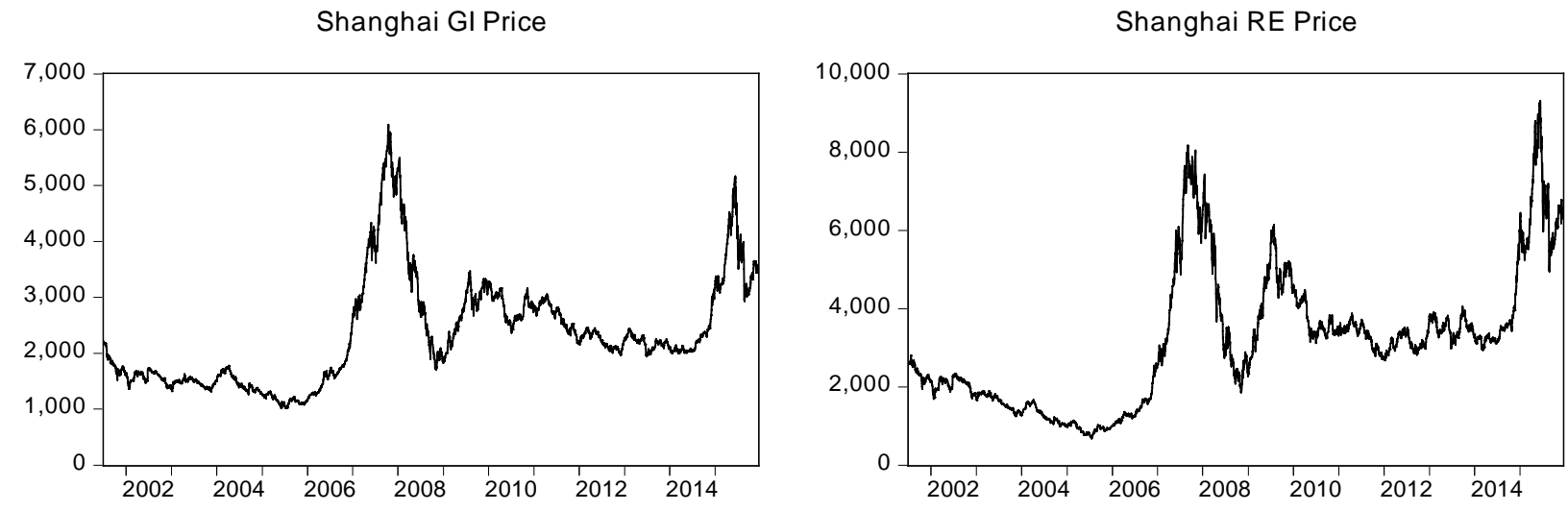

Shenzhen GI Price

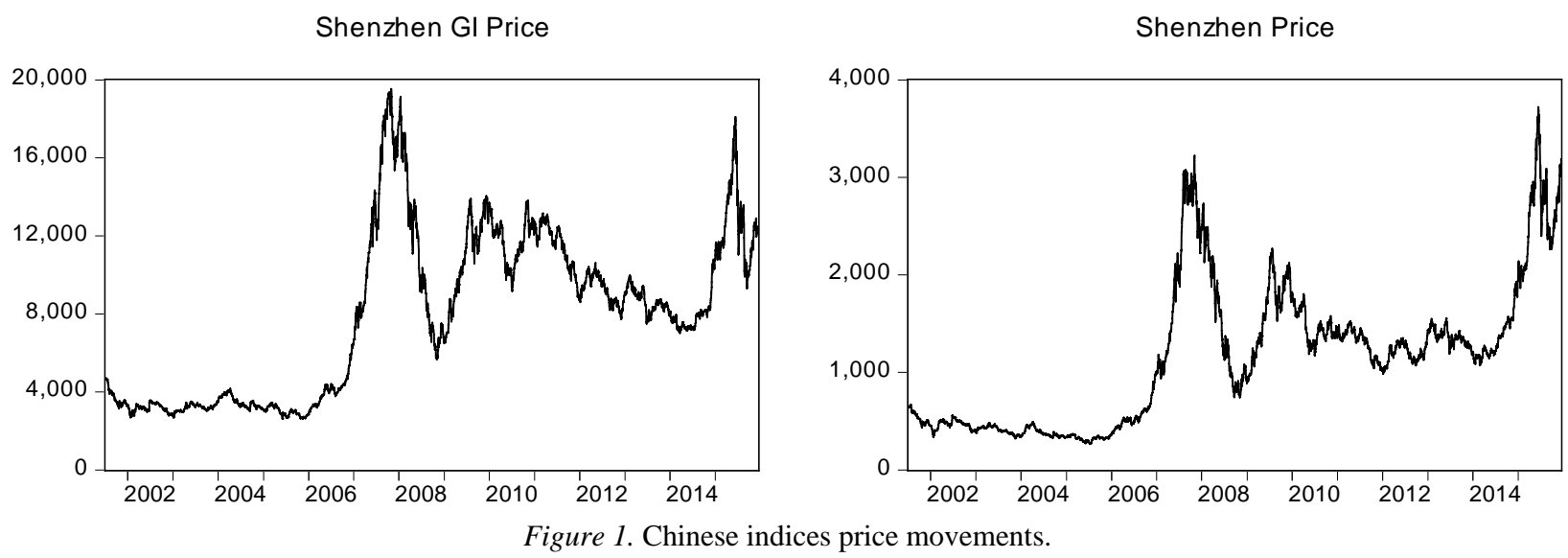

Table 1

Descriptive Statistics of Daily Return Series

\begin{tabular}{lllll}
\hline & SSE_GI & SSE_RE & SZSE_GI & SZSE_RE \\
\hline Mean & 0.000124 & 0.000238 & 0.000260 & 0.000417 \\
Median & 0.000000 & 0.000000 & 0.000000 & 0.000000 \\
Maximum & 0.094008 & 0.095505 & 0.097646 & 0.095065 \\
Minimum & -0.092562 & -0.101253 & -0.097500 & -0.099872 \\
Std. Dev. & 0.016144 & 0.022120 & 0.018008 & 0.021777 \\
Skewness & -0.287811 & -0.267208 & -0.247233 & -0.234791 \\
Kurtosis & 7.602037 & 5.801826 & 6.562457 & 5.511977 \\
Jarque-Bera & $3,380.668$ & $1,278.681$ & $2,033.044$ & $1,026.383$ \\
Observations & 3,772 & 3,772 & 3,772 & 3,772 \\
Correlation matrix & & & & 0.805 \\
SSE & 1 & 0.807 & 0.928 & 0.901 \\
SSE_RE & 0.807 & 1 & 0.819 & 0.855 \\
SZSE & 0.928 & 0.819 & 1 & 1 \\
SZSE_RE & 0.805 & 0.902 & 0.855 & \\
\hline
\end{tabular}


Table 2

GARCH Model Selection-Schwarz Criterion

\begin{tabular}{|c|c|c|c|c|c|c|c|c|}
\hline & Garch $(1,1)$ & Garch $(1,2)$ & Garch $(2,1)$ & Garch $(2,2)$ & Egarch $(1,1)$ & Egarch $(1,2)$ & Egarch $(2,1)$ & Egarch $(2,2)$ \\
\hline Sse_re & -6.0655 & -6.0668 & -6.0717 & -6.0738 & -6.0627 & -6.0651 & -6.0723 & $-6.0746^{*}$ \\
\hline Szse_re & -6.2304 & $-6.2310^{*}$ & -6.2303 & -6.2290 & -6.2198 & -6.2204 & -6.2203 & -6.2170 \\
\hline
\end{tabular}

Note. *the greater Schwarz number in absolute value, suggests the best fitted model.

Table 3

GARCH Coefficients

\begin{tabular}{|c|c|c|c|c|}
\hline \multirow{3}{*}{$\begin{array}{l}\text { Variable } \\
\text { Best model }\end{array}$} & \multicolumn{2}{|c|}{$\begin{array}{l}\text { SSE_RE } \\
\text { (Shanghai real estate index) }\end{array}$} & \multicolumn{2}{|c|}{$\begin{array}{l}\text { SZSE_RE } \\
\text { (Shenzhen real estate index) }\end{array}$} \\
\hline & \multicolumn{2}{|c|}{ EGARCH $(2,2)$} & \multicolumn{2}{|c|}{ GARCH $(1,2)$} \\
\hline & Coefficient & z-Statistic & Coefficient & z-Statistic \\
\hline \multicolumn{5}{|c|}{ Mean equation } \\
\hline$\overline{\beta_{0}}$ & 0.0001 & 0.8359 & 0.0003 & 1.6796 \\
\hline$\beta_{1}$ & $0.0309 *$ & 3.9351 & 0.0102 & 1.2013 \\
\hline$\beta_{2}$ & $1.1020 *$ & 110.57 & $1.0247 *$ & 131.79 \\
\hline \multicolumn{5}{|c|}{ Variance equation } \\
\hline$a_{0}$ & $-0.0549 *$ & -5.5548 & $0.0000^{*}$ & 6.5801 \\
\hline$a_{1}$ & $0.3329 *$ & 14.859 & $0.1151^{*}$ & 10.893 \\
\hline$a_{2}$ & $-0.2955^{*}$ & -14.577 & $0.3465^{*}$ & 3.7891 \\
\hline$a_{3}$ & 0.0005 & 0.2149 & $0.5061 *$ & 6.0943 \\
\hline$a_{4}$ & $1.5592 *$ & 26.724 & -0.0001 & -1.7065 \\
\hline$a_{5}$ & $-0.5624^{*}$ & -9.7202 & & \\
\hline$a_{6}$ & $0.4092 *$ & 4.0887 & & \\
\hline
\end{tabular}

Note. $*$ indicates significance at the 5 percent level or higher.

Shenzhen real estate index returns are also affected by the general index returns of the Shenzhen Stock Exchange. The general index coefficient is statistically significant and positive in the mean equation. This means that the returns of the general index and the real estate index are moving to the same direction. Nevertheless, there is not any statistically significant interaction in the variance equation.

\section{Conclusion}

This is a quantitative study that comprises an overview of the real estate stock indices in China prior to the introduction of the new REIT regime. This study relies on econometric approaches that introduce a generalized autoregressive conditional heteroskedasticity approach in the Chinese real estate related firm stock returns.

The results show that the Chinese stock exchange general index of each stock market has a significant impact on real estate stock index returns. The general index has a positive impact on the Shanghai mean and variance equation. Shenzhen component index has also a positive effect on its real estate index but not any significant effect on the variance equation.

Moreover, the asymmetry of the volatility response to the news seems to be present due to the fact that Shanghai real estate index reports asymmetric transition dynamics for positive and negative shocks. Specifically, bad news has larger effects on volatility of the above listed series. The best fitted EGARCH model shows that the negative shocks at time $t-1$ have a greater impact on the variance at time $t$ than positive shocks. This asymmetry is called leverage effect and its parameter is negative and statistically significant. 
From 2006 to 2007 there is an upward trend that has been followed by a downward movement which reached its lowest point around December 2008. In 2015, there was a second upward movement which hit the roof in the middle of the year. In general, the real estate indices seem to follow their stock market's general index movements.

All the time series have negatively-skewed and leptokurtic distributions. The values of the coefficients of skewness, kurtosis together with the large Jarque-Bera statistics lead to the rejection of the null hypothesis of a normal distribution. The correlation matrix indicates that the correlation among our variables is positive and high (> 0.8). Therefore, some degree of multicollinearity is unavoidably present. Heteroskedasticity is also present as indicated by the high value of the LM-statistic. It is clear that all series exhibit cases of volatility clustering requiring that the estimation should include ARCH-type processes.

In China, REITs are a new investment tool under recent development and due to this the econometric modeling is a useful tool in the observation and understanding of their behavior and characteristics of the prior real estate stock market index. Moreover, the relationship between the general index and the real estate index has a practical implication in terms of asset allocation of a portfolio in the stock market in terms of diversification potentials between general stocks and real estate companies' stocks. The extension of this quantitative study would be interesting in the next years, when REIT time series data would be available.

\section{References}

Bollerslev, T. (1986). Generalized autoregressive conditional heteroskedasticity. Journal of Econometrics, 31(3), $307-327$.

Glosten, L. R., Jagannathan, R., \& Runkle, D. E. (1993). On the relation between the expected value and the volatility of the nominal excess return on stocks. The Journal of Finance, 48(5), 1779-1801.

Gyourko, J., \& Keim, D. B. (1992). What does the stock market tell us about real estate returns? Real Estate Economics, 20, 457-485.

Nelson, D. B. (1991). Conditional heteroskedasticity in asset returns: A new approach. Econometrica, 59(2), 347-370.

Ooi, J. T. L., Newell, G., \& Sing, T.-F. (2006). The growth of REIT markets in asia. Journal of Real Estate Literature, 14(2), 203-222.

Quek, M. C. H., \& Ong, S. E. (2008). Securitising China real estate: A tale of two China centric REITs. Journal of Property Investment \& Finance, 26(3), 247-274.

Schwarz, G. E. (1978). Estimating the dimension of a model. Annals of Statistics, 6(2), 461-464.

Wang, H., Sun, Y., \& Chen, Y. (2009). Special considerations for designing pilot REITs in China. Journal of Property Investment \& Finance, 27(2), 140-161.

Zhang, G. Y., \& Fung, H. G. (2006). On the imbalance between the real estate market and the stock markets in China. Chinese Economy, 39(2), 26-39. 